\title{
Influence of zinc oxide on the physical, structural and optical band gap of zinc silicate glass system from waste rice husk ash
}

\begin{abstract}
Zinc silicate $\left(\mathrm{ZnO}-\mathrm{SiO}_{2}\right)$ glass was fabricated using melt-quench technique with compositions according to the empirical formula $\left[(\mathrm{ZnO})_{\mathrm{x}}(\mathrm{WRHA})_{1-\mathrm{x}}\right]$ which $\mathrm{x}=0.50,0.55,0.57 \mathrm{wt} . \%$. These glass series acquire zinc oxide $(\mathrm{ZnO})$ and white rice husk ash (WRHA) as silica source with two different melting temperatures of $1450{ }^{\circ} \mathrm{C}$ and $1500{ }^{\circ} \mathrm{C}$. Temperature of $1450{ }^{\circ} \mathrm{C}$ and $1500{ }^{\circ} \mathrm{C}$ were chosen in this study because the lowest melting point of $\mathrm{ZnO}-\mathrm{SiO}_{2}$ were at $1475{ }^{\circ} \mathrm{C}$ and by choosing a temperature within the range of $1475{ }^{\circ} \mathrm{C}$ a conclusive study on the best melting point using WRHA substituents can be done. Physical, structural and optical characteristics of fabricated glass samples were analyzed using Energy Dispersive X-ray Fluorescence (EDXRF), X-ray diffraction (XRD), Fourier Transform Infrared Spectroscopy (FTIR) and UV-vis (UV-vis). Optical band gap of the system was obtained by approaching the optical absorption techniques from the Mott-Davis methods. Results indicate that $\mathrm{ZnO}-\mathrm{SiO}_{2}$ glass samples emerge in favors of direct and indirect forbidden transition and increase in $\mathrm{ZnO}$ causes a higher absorption thus resulting in lower band gap. Last but not least, in this study based on the increase of $\mathrm{ZnO}$ content, the glass samples which contains a higher amount of $\mathrm{ZnO}$ has a higher band gap as $\mathrm{Zn}^{2+}$ ions reacts as good network modifier in the glass structure and formed a better arrangement and structure compared to system which has less network modifier.
\end{abstract}

Keyword: Glasses; Zinc oxide; Structural properties; Optical properties; Optical band gap 